Article

\title{
Analysis of Iron Oxide Reduction Kinetics in the Nanometric Scale Using Hydrogen
}

\author{
Swathi K. Manchili *, Johan Wendel, Eduard Hryha and Lars Nyborg \\ Department of Industrial and Materials Science, Chalmers University of Technology, 41296 Gothenburg, Sweden; \\ johan.wendel@chalmers.se (J.W.); hryha@chalmers.se (E.H.); lars.nyborg@chalmers.se (L.N.) \\ * Correspondence: manchili@chalmers.se; Tel.: +46-765-697-796
}

Received: 18 May 2020; Accepted: 25 June 2020; Published: 30 June 2020

check for

updates

\begin{abstract}
Iron nanopowder could be used as a sintering aid to water-atomised steel powder to improve the sintered density of metallurgical (PM) compacts. For the sintering process to be efficient, the inevitable surface oxide on the nanopowder must be reduced at least in part to facilitate its sintering aid effect. While appreciable research has been conducted in the domain of oxide reduction of the normal ferrous powder, the same cannot be said about the nanometric counterpart. The reaction kinetics for the reduction of surface oxide of iron nanopowder in hydrogen was therefore investigated using nonisothermal thermogravimetric (TG) measurements. The activation energy values were determined from the TG data using both isoconversional Kissinger-Akahira-Sunose (KAS) method and the Kissinger approach. The values obtained were well within the range of reported data. The reaction kinetics of $\mathrm{Fe}_{2} \mathrm{O}_{3}$ as a reference material was also depicted and the reduction of this oxide proceeds in two sequential stages. The first stage corresponds to the reduction of $\mathrm{Fe}_{2} \mathrm{O}_{3}$ to $\mathrm{Fe}_{3} \mathrm{O}_{4}$, while the second stage corresponds to a complete reduction of oxide to metallic Fe. The activation energy variation over the reduction process was observed and a model was proposed to understand the reduction of surface iron oxide of iron nanopowder.
\end{abstract}

Keywords: nanopowder; conversion factor; activation energy; thermogravimetry

\section{Introduction}

\subsection{Background}

The use of metal nanopowder instead of the conventional micrometre-sized powder for the powder metallurgical process route in order to manufacture near fully dense material has been of great interest for high performance applications [1]. The use of nanopowder however reduces the green density of conventionally die-pressed compacts owing to poor compressibility. Hence, the increased sintering activity will then necessarily not be enough to bring the material into required densification. One approach would then be the use of it as an additive to conventional powder to improve the densification within the conventional press and sinter route to at least facilitate closed porosity, which would open new opportunities, e.g., post-sintering capsule-free hot isostatic pressing. During the sintering of such powder mix, i.e., conventional micrometre sized powder and nanopowder additive, the nanopowder sinters at low temperatures to initiate early onset of sinter necks and also contributes to overall densification [2]. Sintering, being a surface phenomenon, implies that it is important to understand the surface constituents in order to design a sintering process that is efficient.

Nanoscale materials are of interest owing to their modified solid-state properties compared to conventional solids [3]. Nanosized metal powder are being produced and extensively used for a wide range of applications. The principal interest stems from the properties that nanomaterials possess owing to their excess surface energy. This excess surface energy contributes to the extraordinary chemical 
characteristics like melting point depression and reduced activation energy for oxide reduction $[4,5]$. Deviation in the melting temperature is observed with an increased proportion of surface atoms when the particle size is reduced beyond a critical value [6], typically about $10 \mathrm{~nm}$.

Iron nanopowder is hence used in the present research as an additive to improve the density of water-atomized iron powder compacts. The iron nanopowder was found to be covered with an oxide scale of $3 \mathrm{~nm}$ thick [7]. For the sintering process to be efficient, this surface oxide on the metal particle must at least in part be reduced. The reduction of surface oxide is a necessary must for the metallurgical bonds to form between the metal particles comprising the compact; which in turn is crucial for achieving the structural strength of the PM component. This study aims at understanding the reaction kinetics for reduction of the aforementioned oxide scale on the iron nanopowder when heated in pure hydrogen. Investigation on the reduction kinetics of the micron meter sized powder has already been studied [8]. Iron nanopowder of two different size fractions was investigated and thermogravimetry was applied to depict the reduction kinetics. Two different size fractions were studied as this study is part of a larger effort to understand how nanopowder enhances densification in water atomised steel powder. Then, the activation energy (E) was evaluated using two different approaches, namely the isoconversional Kissinger-Akahira-Sunose (KAS) method and Kissinger approach. A similar exercise was carried out on $\mathrm{Fe}_{2} \mathrm{O}_{3}$ reference material to develop a systematic understanding of the reduction kinetics for the presumed main constituent of the oxide layer. The study hence aims to clarify the governing fundamental factors for the reduction of the surface oxide layer.

\subsection{Theory}

The methods used for kinetic analysis can be categorized based on experimental conditions and mathematical analysis used. Mathematical models are further divided into model fitting and isoconversional methods. Isoconversional methods are known as model-free methods. In the case of nonisothermal studies, model fitting methods are not preferred due to various reasons. They assume that the kinetic parameters like pre-exponential parameter (A), activation energy (E) are constant and use a single heating rate curve to fit the parameters [9]. Activation energy and pre-exponential factor are assumed to remain constant during solid-state reactions but they seem to vary as the reaction progresses [10]. Isoconversional methods are used to investigate this variation. Isoconversional methods have become popular in comparison to the model fitting methods. They are based on data from several experiments, and the reaction rate at a particular degree of conversion is considered to be a function of temperature. The model-free kinetics analysis uses this variation for evaluating the reaction mechanism but the disadvantage with this approach is that the pre-exponential factor cannot be directly evaluated. A series of experiments at different heating rates are to be conducted to be able to use isoconversional methods [11].

The calculations for the apparent activation energy in this study have been performed using nonisothermal experimental data. In this study, activation energy is calculated using two different approaches, namely the isoconversional and Kissinger approaches.

In a gas/solid reaction, the basic reaction considered is gas reacting with solid yielding a product. The rate of reaction, which is the change in the concentration of the reactants or the products over the change in time, can be described according to the following equation:

$$
\text { Rate }=\frac{-[g a s]}{d t}=k[g a s]^{n}
$$

where [gas] is the gas concentration, $n$ is the order of the reaction, and $k$ is the rate constant.

When the rate constant $k$ relates with temperature through activation energy, it is given in the form of Arrhenius equation:

$$
k=A e^{\frac{-E}{R T}}
$$


where $E$ is the activation energy, $R$ is the universal gas constant, $A$ is frequency or pre-exponential factor, and $T$ is temperature.

The progress or extent of the reaction or the conversion fraction of a reaction is given by $\alpha$ as:

$$
\alpha=\frac{m_{i}-m}{m_{i}-m_{f}}
$$

where $m_{i}$ is the initial mass, $m$ is the actual mass, and $m_{f}$ is the final mass of the sample under kinetic study.

The reaction rate can be described as:

$$
\frac{d \alpha}{d t}=k f(\alpha)
$$

where $f(\alpha)$ is the function to explain the reaction model. The above equation is integrated for integral rate law according to:

$$
\int_{0}^{\alpha} \frac{d \alpha}{f(\alpha)}=g(\alpha)=k t
$$

where $g(\alpha)$ is the function to explain the integration reaction model. Based on $f(\alpha)$ and $g(\alpha)$, the solid-gas reaction models, namely Avrami-Erofeev model, unimolecular model, 1-D, 2-D, and 3-D models, and power law model, are proposed [12].

Combining Equations (2) and (5), we get:

$$
g(\alpha)=A e^{-E / R T} t
$$

Expressing the reaction rate as a function of temperature for nonisothermal systems is done by using the expression as follows:

$$
\frac{d \alpha}{d T}=\frac{d \alpha}{d t} \frac{d t}{d T}
$$

where $\frac{d T}{d t}$ is the heating rate represented by $\beta$. Thus, the Equation (7) above can be rewritten as:

$$
\frac{d \alpha}{d T}=\frac{k f(\alpha)}{\beta}
$$

Using Equation (2), the Equation (8) can be further rewritten as:

$$
\frac{d \alpha}{d T}=\frac{A}{\beta} e^{-E / R T} f(\alpha)
$$

Integrating Equation (9) yields:

$$
\begin{gathered}
\int_{0}^{\alpha} \frac{d \alpha}{f(\alpha)}=\frac{A}{\beta} \int_{T_{o}}^{T} e^{-E / R T} d T \\
g(\alpha)=\frac{A}{\beta} \int_{T_{o}}^{T} e^{-E / R T} d T
\end{gathered}
$$

This equation can be rewritten as:

$$
g(\alpha)=\frac{A E}{\beta R} p(x)
$$

where $x=\frac{E}{R T}$ and $p(x)$ is the exponential integral.

There are different isoconversional methods to evaluate $E$ at different degrees of conversion, $\alpha$. The Ozawa, Flynn and Wall method uses a plot of $\log \beta$ verses $\frac{1}{T}$ plot whose slope gives $E$ for a 
particular $\alpha$ [13]. There are other methods like the Friedman method and the nonlinear Vyazovkin method which have their own set of advantages or disadvantages [14,15].

This study used the Kissinger-Akahira-Sunose (KAS) method, for which Equation (9) can be integrated and rearranged as follows:

$$
\ln \frac{\beta}{T^{2}}=-\frac{E}{R T}+\ln \left(\frac{A E}{g(\alpha) R}\right)
$$

where the term $\ln \left(\frac{A E}{g(\alpha) R}\right)$ is independent of $T$ and $\beta$. For a particular $\alpha$, the slope of the plot $\ln \frac{\beta}{T^{2}}$ versus $\frac{1}{T}$ obtained at different heating rates yields the activation energy.

\section{The Kissinger Method}

The Kissinger method is based on a series of experiments in which the sample is heated at different heating rates $(\beta)$, whereby the activation energy can be determined from the correlation between maximum mass loss at so called peak temperature. The peak temperature, $T_{m}$, for the reduction reaction is measured for each heating rate. This peak temperature is hence when the mass loss rate is the highest. A plot is constructed of $\ln \left(\frac{\beta}{T_{m}^{2}}\right)$ versus $\frac{1}{T_{m}}$ and a linear relation is fitted to the data. The slope obtained is $\frac{-E}{R}$ where $E$ is the activation energy and $R$ is the gas constant [16]. This approach was used to derive the activation energy for the reduction of both the Fe nanopowder and the $\mathrm{Fe}_{2} \mathrm{O}_{3}$ reference nanopowder.

\section{Materials and Methods}

Iron nanopowder of two different size fractions, namely $40-60$ and $60-80 \mathrm{~nm}$, was acquired from Sigma-Aldrich, Germany. The purity of the metal powder was higher than $99.5 \mathrm{wt}$. \%. The reference $\mathrm{Fe}_{2} \mathrm{O}_{3}$ nanopowder was also obtained from the same source. The size of the oxide powder was less than $50 \mathrm{~nm}$. The morphology of both metal and oxide powder was spherical.

X-ray photoelectron spectroscopy (XPS) was carried out using a PHI 5000 Versaprobe III (Physical Electronics Inc, Chanhassen, MN, USA) X-ray photoelectron spectrometer equipped with monochromatic $\mathrm{AlK}_{\alpha}(1486.6 \mathrm{eV}) \mathrm{X}$-ray source. The XPS was carried out to know the chemistry of oxide scale on the iron nanopowder. Narrow scans were carried out using $69 \mathrm{eV}$ pass energy and the data analysis was performed using MultiPak software, version 9.7 ((Physical Electronics Inc, Chanhassen, MN, USA). X-ray diffraction was performed on the oxide nanopowder using a Bruker AXS D8 Advance diffractometer (Karlsruhe, Germany) with $\mathrm{CrK}_{\alpha}$ radiation operated at $35 \mathrm{kV}$ and $50 \mathrm{~mA}$. The scanning range of $30-158^{\circ}$ with a step size of $0.02^{\circ}$ at $2.5 \mathrm{sec} / \mathrm{step}$ was employed.

To investigate the reduction kinetics, thermogravimetric analysis was performed using a simultaneous thermal analyzer STA449 (NETZSCH Thermal Analysis GmbH, Germany). A small alumina crucible was used as a vessel for the sample to be analyzed. Crucible along with the sample was placed in the middle of the vertical furnace on top a thermocouple pole. Before the experiment, the furnace was evacuated and then flushed with argon gas. The mass of the samples used for thermogravimetric analysis (TG) was $100 \pm 10 \mathrm{mg}$. The powder sample was heated from room temperature to $1000 \mathrm{~K}$ under high purity hydrogen atmosphere $(99.9999 \%$ purity) at various heating rates of $5,7,10,15,20,25,30,40$, and $50 \mathrm{~K} / \mathrm{min}$. Constant flow rate of $100 \mathrm{~mL} / \mathrm{min}$ of the high purity hydrogen gas was employed. Scientific purity argon gas was used as protective gas at a constant flow rate of $20 \mathrm{~mL} / \mathrm{min}$. Mass loss is recorded as a function of temperature under controlled atmosphere. As described in the theory section, the activation energy for the hydrogen-driven reduction of the oxide layer on the $\mathrm{Fe}$ nanopowder and the $\mathrm{Fe}_{2} \mathrm{O}_{3}$ was calculated by plotting the obtained data from TG curves in an Arrhenius relation based on the estimation procedure described in the calculation of reduction kinetics section above. 


\section{Results and Analysis}

\subsection{Iron Nanopowder}

\subsubsection{Non-Isothermal Reduction of Oxide Layer on Fe Nanopowder}

Figure 1 shows the thermogravimetry results for hydrogen-driven reduction of oxide layer on the iron nanopowder. Figure $1 \mathrm{a}, \mathrm{b}$ shows the heating stage of the reduction for the iron nanopowder size range of $40-60 \mathrm{~nm}$ and $60-80 \mathrm{~nm}$, respectively, at different heating rates.
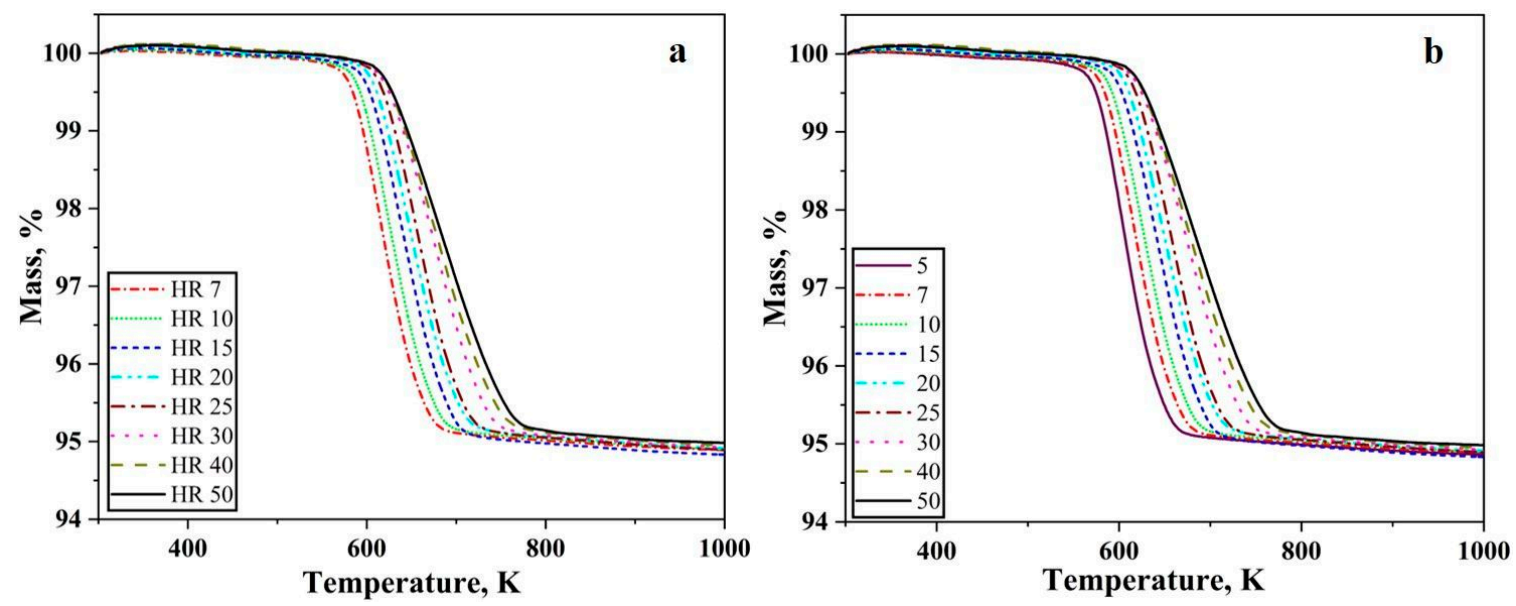

Figure 1. TG graphs for the reduction of oxide layer on Fe nanopowder in pure hydrogen up to $1000 \mathrm{~K}$, showing results for size ranges (a) 40-60 and (b) 60-80 nm, respectively. The numbers in the inserts show the different heating rates applied in $\mathrm{K} / \mathrm{min}$.

A total loss of around 5\% was recorded independent on heating under all the conditions for both the nanopowder. The reduction process commences around $573 \mathrm{~K}$ and is completed below $773 \mathrm{~K}$ depending on the heating rate. Hence, as the heating rate was increased, the reduction process gradually shifted to higher temperatures, i.e., the start and end of the reduction process occurs at higher temperature. The slope of the curves remains similar with changing heating rate. The mass loss recorded corresponds to the reduction of the surface oxide.

Figure 2a,b shows the first differential of the TG curves for reduction of oxide layer on iron nanopowder in the hydrogen at different heating rates for the size ranges of 40-60 nm and 60-80 nm, respectively. A single peak was observed in both the cases. The peak temperature was found to vary from 603 to $713 \mathrm{~K}$ for the $40-60 \mathrm{~nm}$ particle sizes with peak temperature being about $630 \mathrm{~K}$ for the heating rate of $7 \mathrm{~K} / \mathrm{min}$ and about $713 \mathrm{~K}$ for $50 \mathrm{~K} / \mathrm{min}$. In the case of $60-80 \mathrm{~nm}$ particle size, the peak temperature varied from 599 to $685 \mathrm{~K}$ with about $600 \mathrm{~K}$ being the peak temperature for $5 \mathrm{~K} / \mathrm{min}$ and about 684 for $50 \mathrm{~K} / \mathrm{min}$. The peak temperature of the DTG curves increases with increasing heating rate. Broadening of the peaks was observed as the heating rate increased. This peak temperature is used for calculating the apparent activation energy for the reduction reaction through Kissinger approach.

The metal particles are invariably covered by an oxide scale. The nanopowder particles are no exception to this fact. Metal nanopowder particles have core-shell structure, where the core is metal, and the shell is the oxide layer. The oxide scale on the metal particles must be reduced at least in part for the necks to form between them and subsequently for sintering to proceed. To understand the chemical constituents of the oxide scale techniques like X-ray photoelectron spectroscopy, Auger electron spectroscopy can be used. The thickness of the oxide scale can also be evaluated by applying different models using the thermogravimetric data obtained as above. For the case of water-atomized powder, the thickness has been assessed using XPS and has been found to be in the range of 4-7 nm [17]. The authors in their previous work have performed microstructural and surface characterization of the 
iron nanopowder used in the present study where the thickness of the oxide scale has been determined to be $3 \mathrm{~nm}$ [7]. The mass loss data in Figure 1 corresponds to the reduction of the above-mentioned oxide scale. Figure 3 shows that the oxide scale consists predominantly of $\mathrm{Fe}_{2} \mathrm{O}_{3}$. Yamashita et al. [18] have performed XPS investigations on $\mathrm{Fe}_{2} \mathrm{O}_{3}$ and $\mathrm{Fe}_{3} \mathrm{O}_{4}$ samples and found that the $2 \mathrm{p}_{3}$ peak appears at $711.0 \mathrm{eV}$ and $3 p$ peak appears at $55.6 \mathrm{eV}$ for $\mathrm{Fe}_{2} \mathrm{O}_{3}$. The binding energies from literature correspond well with the peak positions obtained in the present study confirming that the oxide scale consists of $\mathrm{Fe}_{2} \mathrm{O}_{3}$. The TG and DTG curves show a single stage reduction of $\mathrm{Fe}_{2} \mathrm{O}_{3}$ to Fe.
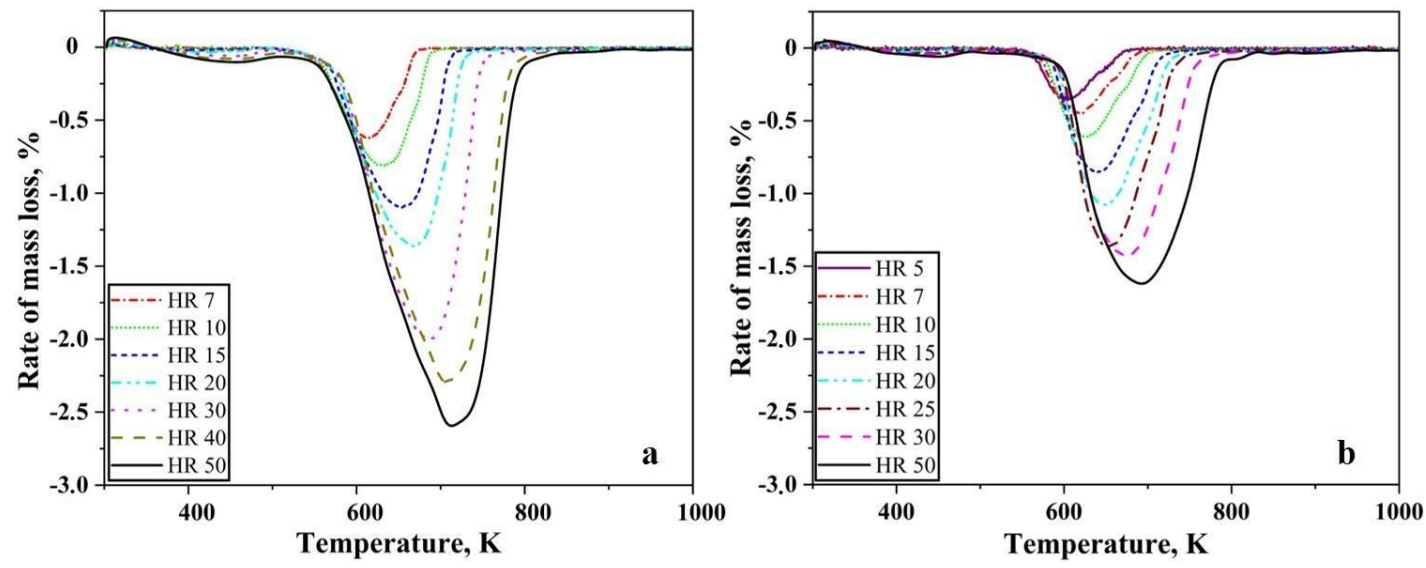

Figure 2. DTG curves for Fe nanopowder heated in pure hydrogen atmosphere, showing results at different heating rates in $\mathrm{K} / \mathrm{min}$ for the sizes ranges (a) 40-60 nm, (b) 60-80 nm, respectively.
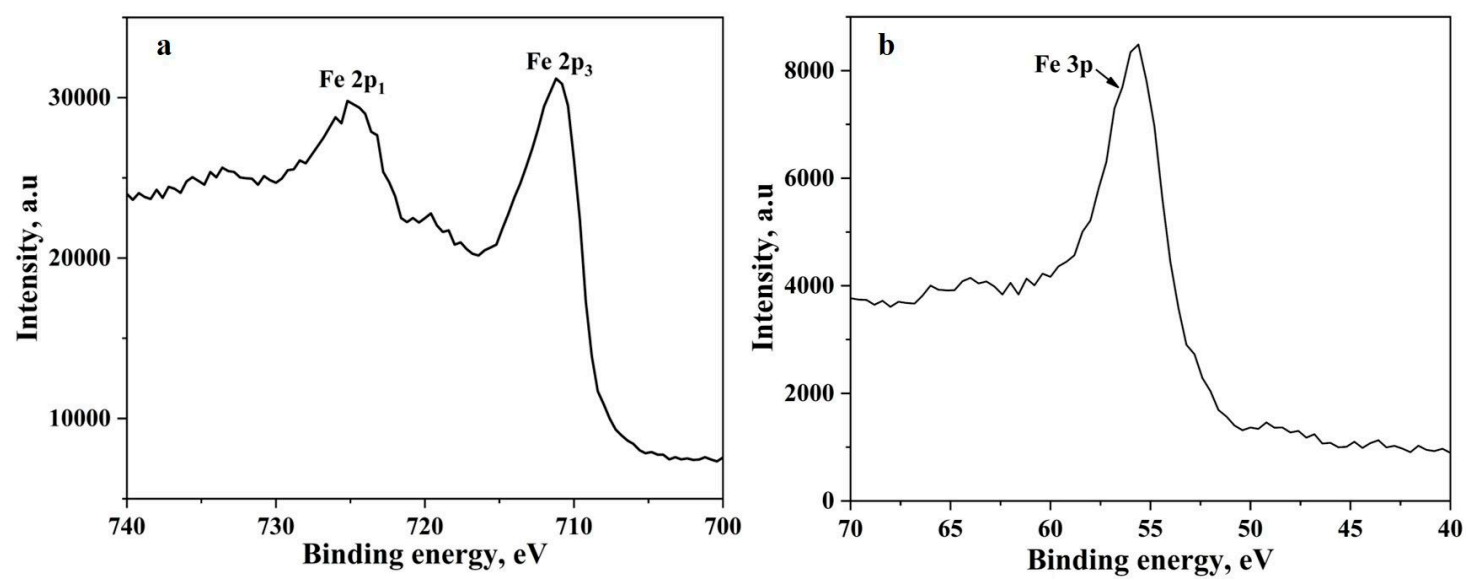

Figure 3. The XPS spectra of (a) Fe 2p peaks and (b) Fe 3p peak obtained from the iron nanopowder.

\subsubsection{Reduction Kinetics for Removal of Oxide Layer on Fe Nanopowder}

The reduction kinetics in this study has been addressed in terms of the extent of reaction or extent of conversion by a factor of conversion, $\alpha$. The conversion fraction is obtained using Equation (3).

Figure 4 shows the plots with varying degree of conversion for the reduction of the oxide film on the Fe nanopowder under hydrogen atmosphere for different heating rates against temperature. This is calculated based on the evaluation of conversion of the reduction reaction using Equation (3) and the temperature corresponding to the particular $\alpha$, is taken from the TG curves. The total mass loss recorded from the TG is considered as complete reduction (100\%) and total mass loss, in this case $5 \%$, is taken as $\alpha=1.0$. Further calculations for different levels of conversion are done based on this.

There is no change in the behavior of the curves at different heating rates. The broadening of the peaks for higher heating rates is reflected in Figure 4 as the curves for higher heating rate have a broadening effect. As the reduction of the surface oxide is supposed to be a single stage process for Fe nanopowder, the slope appears basically the same. 

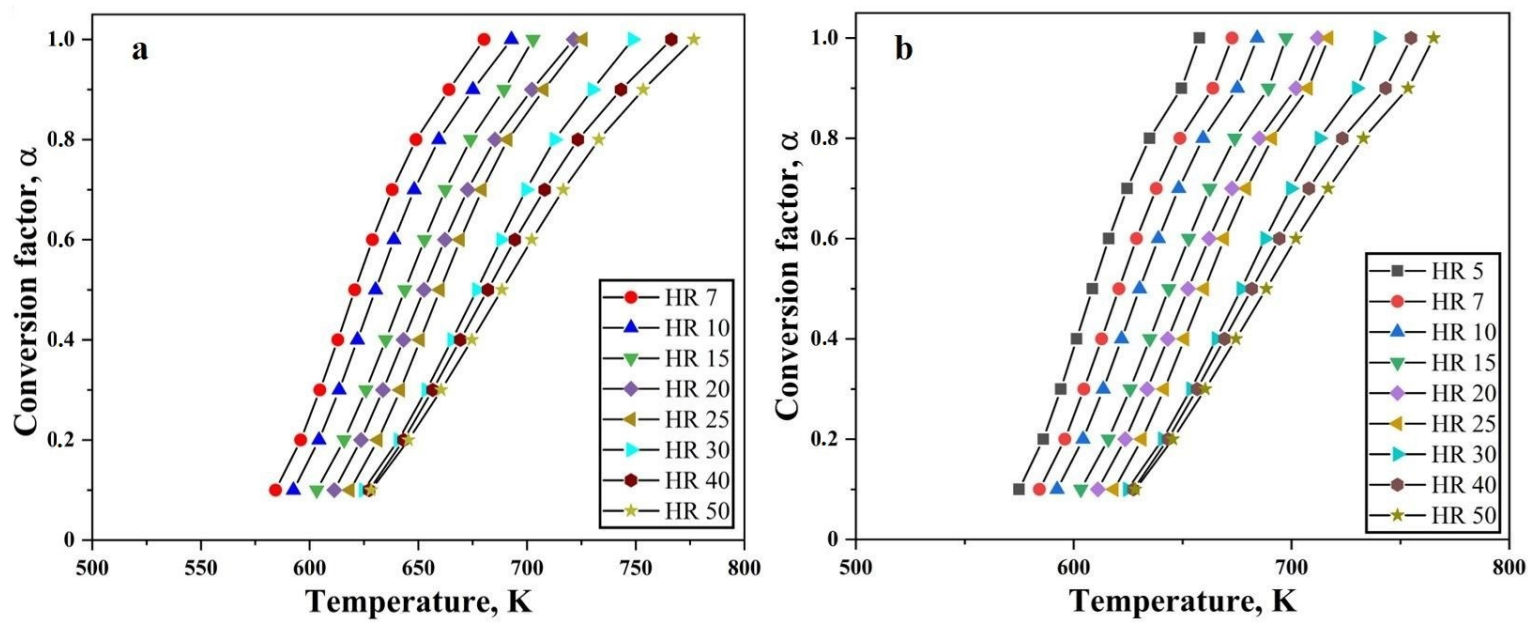

Figure 4. Variation of conversion factor as function of temperature at different heating rates for reduction of oxide film on Fe nanopowder of particle size ranges (a) 40-60 nm and (b) 60-80 nm, respectively.

It has already been established that the isoconversional methods for kinetics analysis use the exact temperature where a certain extent of conversion or reduction occur, and such exercise is iterated at different heating rates. The degree of conversion from 0.1 to 1.0 is investigated for the oxide film on Fe nanopowder, and from 0.03 to 1.0 for the reference $\mathrm{Fe}_{2} \mathrm{O}_{3}$ nanopowder. A plot is drawn using Equation (12) by utilizing the absolute temperature, degree of conversion for particular heating rate and multiple heating rate and degree of conversion data are then combined into a single plot (Figure 5). All the slopes in Figure 5a,b look similar at every condition of $\alpha$.
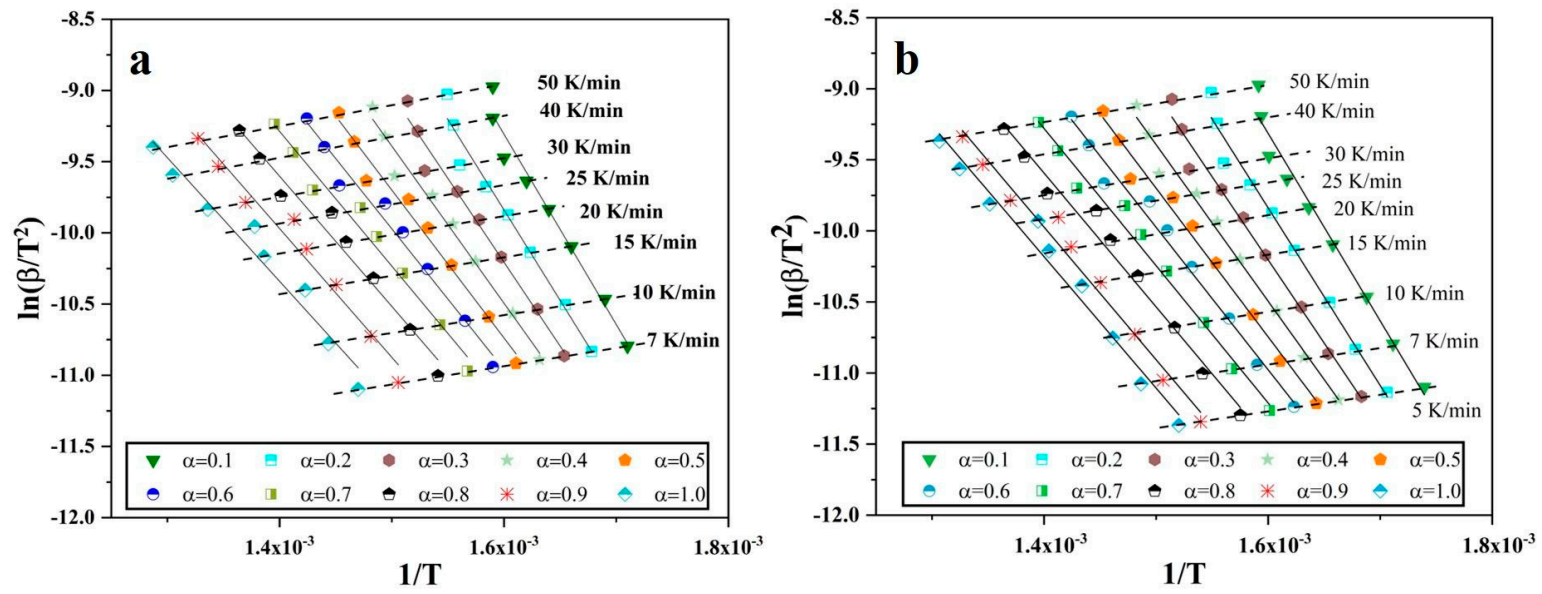

Figure 5. Plots of $\ln \frac{\beta}{T^{2}}$ vs. $\frac{1}{T}$ for different degree of conversion of oxide film and heating rates for Fe nanopowder of size ranges (a) 40-60 and (b) 60-80 nm, respectively.

After plotting, least square linear fitting was applied to each set of points, where each set consists of 10 points that correspond to different heating rates for specific degree of conversion. The slope of the fit was taken that is $-\frac{E}{R}$, so the slope is then multiplied by $-R$ to yield the value of apparent activation energy E. Through this way, the $\mathrm{E}$ was calculated for different degree of conversion, in the case of Fe nanopowder from 0.1 to 1.0. Figure 6 is the plot of the calculated activation energy at different degree of conversion.

The apparent activation energy for the reduction of surface oxide in Fe nanopowder for two different size grades varies from 65 to 118 and 71 to $115 \mathrm{~kJ} / \mathrm{mol}$ for the $40-60$ and $60-80 \mathrm{~nm}$ sizes of Fe nanopowder, respectively. Hence, an overall decrease in the value of apparent activation energy was observed as the reduction process proceeds. For both the size fractions of Fe nanopowder, the activation 
energy values were in the same range over varying degrees of conversion. From $0.1<\alpha<0.7$, the apparent activation energy values for both particle size ranges remained the same, while for the final stage of reduction, the values differed slightly.

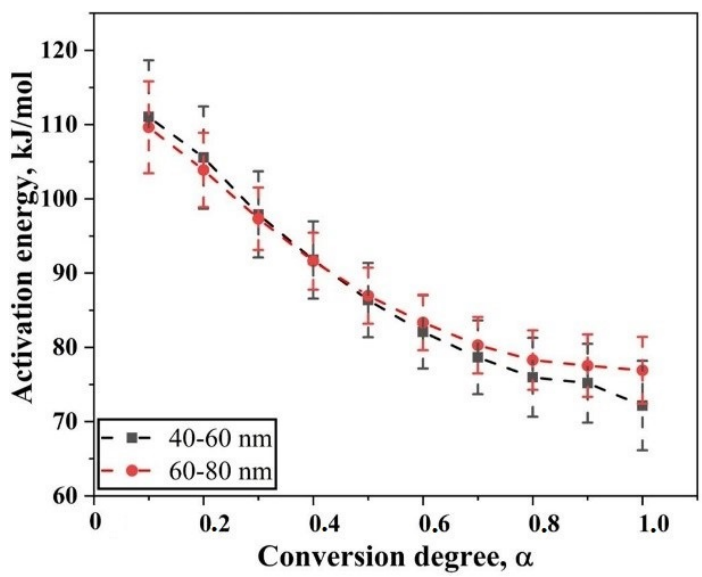

Figure 6. Plot showing the variation of apparent activation energy as the degree of conversion of the reduction of oxide film on Fe nanopowder of sizes $40-60 \mathrm{~nm}$ and $60-80 \mathrm{~nm}$, respectively. The plot also indicates the scatter in the derived value of activation energy.

\subsection{Iron Oxide Nanopowder}

\subsubsection{Non-Isothermal Reduction of $\mathrm{Fe}_{2} \mathrm{O}_{3}$ Nanopowder}

Figure 7 shows the TG curves of the $\mathrm{Fe}_{2} \mathrm{O}_{3}$ nanopowder under hydrogen atmosphere for the heating up to $923 \mathrm{~K}$ and $623 \mathrm{~K}$ at various heating rates.
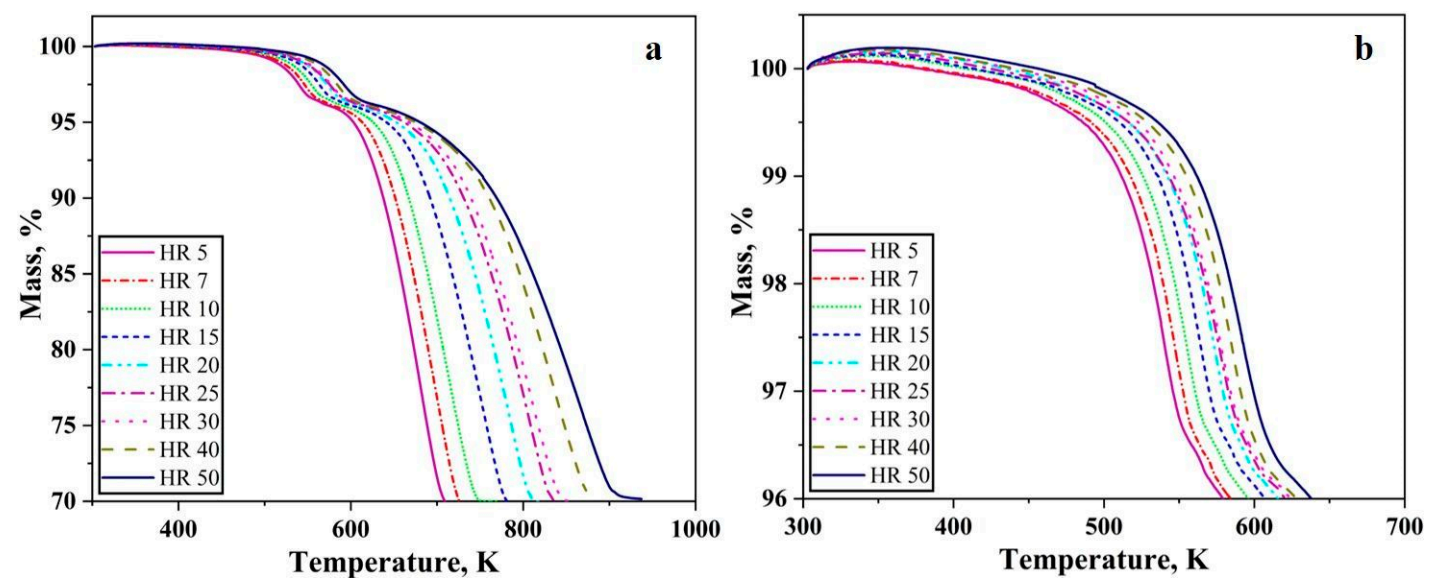

Figure 7. TG graphs of $\mathrm{Fe}_{2} \mathrm{O}_{3}$ nanopowder reduced in hydrogen atmosphere at various heating rates (a) till $973 \mathrm{~K}$ (b) till $623 \mathrm{~K}$.

The total mass loss of 30\% was recorded at various heating rates. This mass loss corresponds well to the removal of oxygen from $\mathrm{Fe}_{2} \mathrm{O}_{3}$ in accordance with its composition, which essentially means that the reduction of $\mathrm{Fe}_{2} \mathrm{O}_{3}$ to $\mathrm{Fe}$ was complete at all conditions. As the heating rate increases, the TG curve gets broader. In other words, the reduction process is slowed down as the heating rate increases and attains a completion at higher temperatures. The start of the reduction process is also retarded with an increase in the heating rate. For a heating rate of $5 \mathrm{~K} / \mathrm{min}$, the complete reduction of the oxide finishes before the temperature reaches $723 \mathrm{~K}$ whereas in the case of $50 \mathrm{~K} / \mathrm{min}$ complete reduction occurs around $923 \mathrm{~K}$. Two different slopes were clearly observed from Figure 7a. Slope change is 
observed at around $3.5 \%$ mass loss or $96.5 \%$ remaining mass. For a heating rate of $5 \mathrm{~K} / \mathrm{min}$, the change in slope is observed at around $553 \mathrm{~K}$ whereas for $50 \mathrm{~K} / \mathrm{min}$ it is $598 \mathrm{~K}$ (Figure $7 \mathrm{~b}$ ).

The slope change of TG curves can be interpreted or understood better when the first differential is taken. Figure 8 shows the DTG curve of $\mathrm{Fe}_{2} \mathrm{O}_{3}$ nanopowder reduced under hydrogen atmosphere at various heating rates. For all the heating rates the DTG curve is composed of two peaks namely, T1 and T2 (Figure 8a). These two peaks for all the heating rates occur in a temperature range of $533<\mathrm{T} 1<593 \mathrm{~K}$ and $683<\mathrm{T} 2<863 \mathrm{~K}$. For heating rates 5, 7, 10, and $15 \mathrm{~K} / \mathrm{min}$, there is a small peak between observed between the first and second peaks (Figure $8 \mathrm{~b}$ ). This small peak merges with the first peak as the heating rate increases and it occurs in the temperature range of 563 to $603 \mathrm{~K}$. There is a broadening of the second peak with increasing heating rate as the temperature to complete the reduction process also increases.
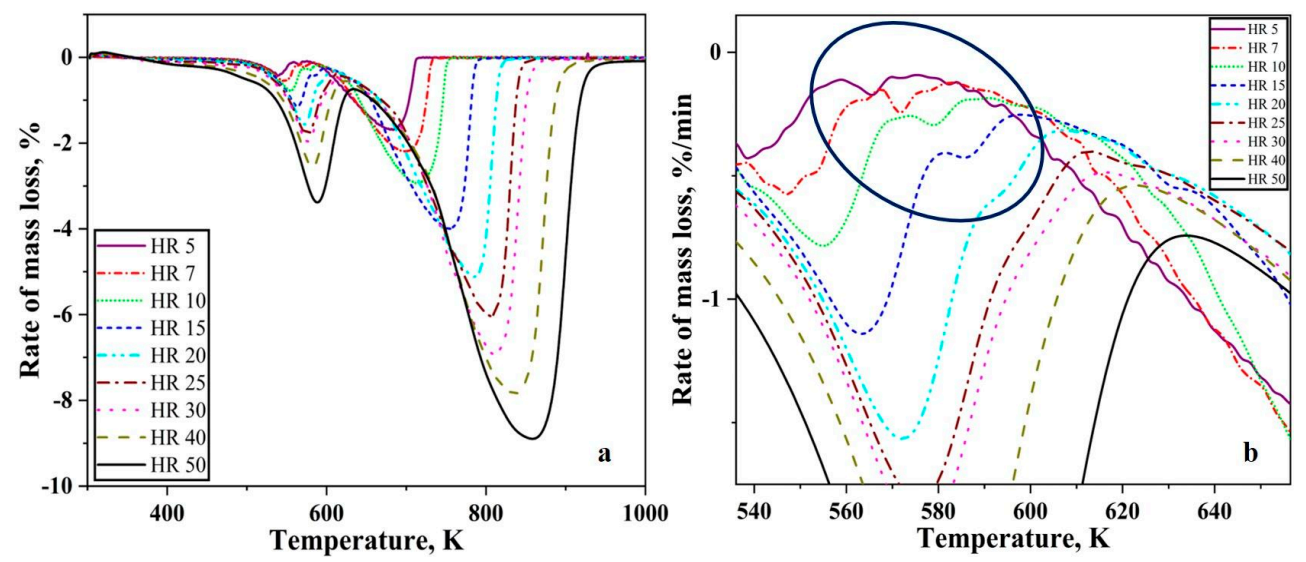

Figure 8. DTG curves of $\mathrm{Fe}_{2} \mathrm{O}_{3}$ nanopowder reduced in hydrogen atmosphere (a) complete curves,

(b) showing a small peak in some of the DTG curves.

The slope of the TG curves in Figure 7a change as the temperature increases. For the convenience of understanding, the TG curve can be divided into two stages. The first stage corresponds to the reduction of $\mathrm{Fe}_{2} \mathrm{O}_{3}$ to $\mathrm{Fe}_{3} \mathrm{O}_{4}$ as a mass loss of around $3.5 \%$ which is close to the theoretical value of $3.34 \%$. This is the prereduction step in the reduction of $\mathrm{Fe}_{2} \mathrm{O}_{3}$ to Fe prior to the second stage where the complete reduction to metal iron occurs. Therefore, the reduction process proceeds in two stages, $\mathrm{Fe}_{2} \mathrm{O}_{3} \rightarrow \mathrm{Fe}_{3} \mathrm{O}_{4} \rightarrow$ Fe. This two-stage reduction agrees well with previous literature studies which report that the reduction proceeds in these two stages [9,19]. When reduced under isothermal conditions below $843 \mathrm{~K}$, either $\mathrm{Fe}_{2} \mathrm{O}_{3}$ and $\mathrm{Fe}_{3} \mathrm{O}_{4}$ or $\mathrm{Fe}_{3} \mathrm{O}_{4}$ and $\mathrm{Fe}$ exist at any point throughout the experiment [20]. For the same amount of mass loss, at higher heating rates the residence time for the sample is reduced. Therefore, it must lose more mass during the reduced residence time. Hence, we see deeper peaks at higher heating rates. For the DTG curves, the peaks whose maxima is located between 533 and $593 \mathrm{~K}$ correspond to the reduction of $\mathrm{Fe}_{2} \mathrm{O}_{3}$ to $\mathrm{Fe}_{3} \mathrm{O}_{4}$ and the peaks whose maxima is located between 683 and $863 \mathrm{~K}$ correspond to the second reduction step from $\mathrm{Fe}_{3} \mathrm{O}_{4}$ to metallic iron.

The peak temperatures at different heating rates for $\mathrm{Fe}$ nanopowder and $\mathrm{Fe}_{2} \mathrm{O}_{3}$ nanopowder experiments are shown in Figure 9. The peak temperatures for Fe nanopowder lie in between the first and the second peaks of the $\mathrm{Fe}_{2} \mathrm{O}_{3}$ nanopowder. The scale is composed of $\mathrm{Fe}_{2} \mathrm{O}_{3}$ which is reduced in a single step to Fe. The peak temperature for reduction of the oxide film on Fe nanopowder is hence approximately an average of the peak values of the reference $\mathrm{Fe}_{2} \mathrm{O}_{3}$ nanopowder.

The oxide covering the iron nanopowder is reduced in a single step whereas the oxide nanopowder undergoes a two-step reduction process. 


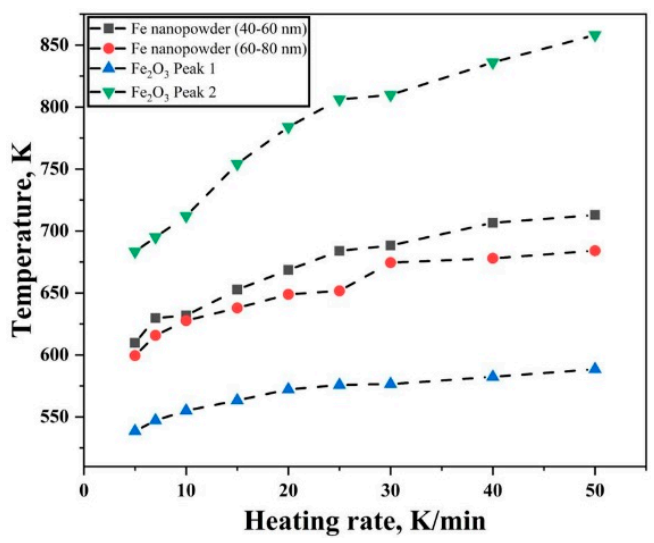

Figure 9. Peak temperature variation taken from DTG curves for reduction of oxide film on Fe nanopowder and reference $\mathrm{Fe}_{2} \mathrm{O}_{3}$ nanopowder.

\subsubsection{Reduction Kinetics for $\mathrm{Fe}_{2} \mathrm{O}_{3}$ Nanopowder}

A total mass loss of $30 \%$ was observed when $\mathrm{Fe}_{2} \mathrm{O}_{3}$ nanopowder was reduced under hydrogen atmosphere in the TG. Hence, this total mass loss of $30 \%$ means $\alpha=1.0$. The degree of conversion is therefore taken at different stages of reduction namely, from 0.03 to 1.0. Figure 10 shows the changes in the degree of conversion as function of temperature at varying heating rates for $\mathrm{Fe}_{2} \mathrm{O}_{3}$ nanopowder reduced under hydrogen atmosphere. It can be clearly seen that the slope of the curves changes around $\alpha<0.2$. This is an indication that the nature of reaction is changed. Figure $10 \mathrm{~b}$ shows that slope change is observed around $\alpha=0.12$. This slope change is in line with the change observed from TG curves where a slope change was observed at $3.5 \%$ mass loss.
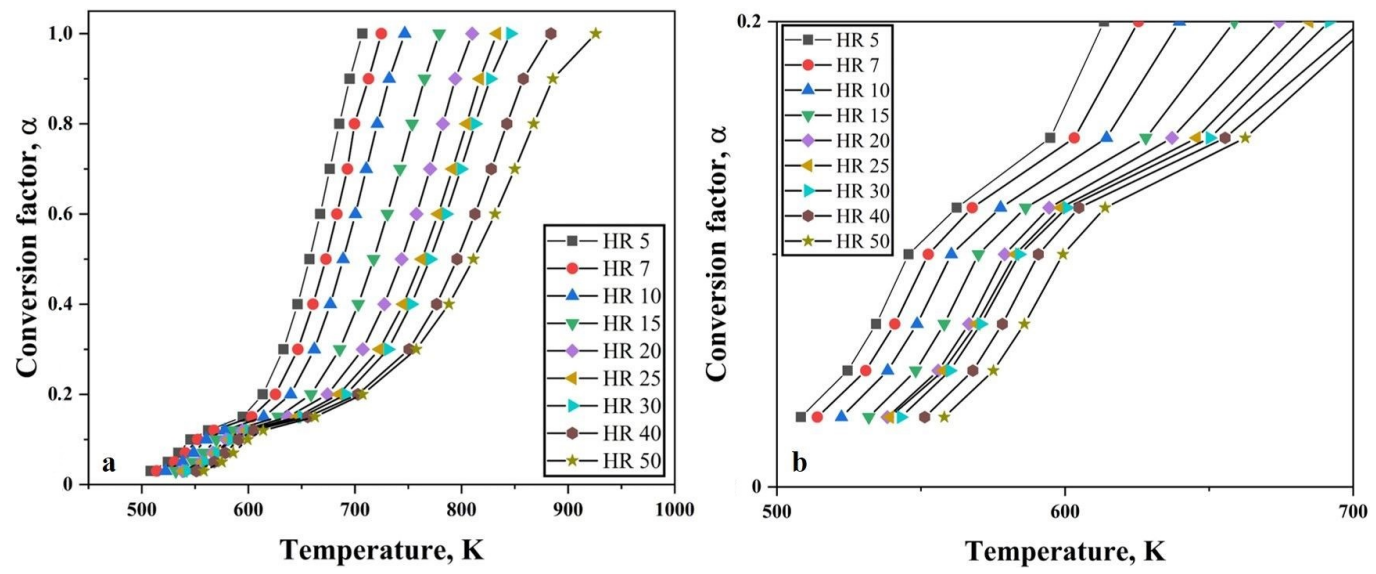

Figure 10. Variation observed in degree of conversion as function of temperature at varying heating rates for (a) complete heating range and (b) close-up view showing the slope change.

The change in the slope of the curves at $\alpha=0.12$ or when the mass loss is $3.5 \%$ is attributed to the conversion of $\mathrm{Fe}_{2} \mathrm{O}_{3}$ to $\mathrm{Fe}_{3} \mathrm{O}_{4}$. Beyond this, the main reduction step, which is $\mathrm{Fe}_{3} \mathrm{O}_{4}$ to $\mathrm{Fe}$ commences. Similar studies carried out by Paurghahramani et al. [9] revealed both magnetite and hematite phases by means of X-ray analysis of the reduced products of sample heated to $450{ }^{\circ} \mathrm{C}$. Change in the slope was also observed as the degree of conversion reached 0.11 .

The isoconversional plots $\left(\ln \frac{\beta}{T^{2}}\right.$ vs. $\frac{1}{T}$ ) for different degrees of conversion of $\mathrm{Fe}_{2} \mathrm{O}_{3}$ are plotted in Figure 11. Similar to Figure 8, each set of points have been least-square fitted linearly and the slope was multiplied with $-\mathrm{R}$ to yield the apparent activation energy value for various values of $\alpha$. The slope of the curves change as the value of $\alpha$ is increased. Beyond $\alpha=0.12$, a change is seen in the 
slope of the curves. For $0.3<\alpha<1.0$, the curves have a similar slope. This indicates a change in the reduction reaction.

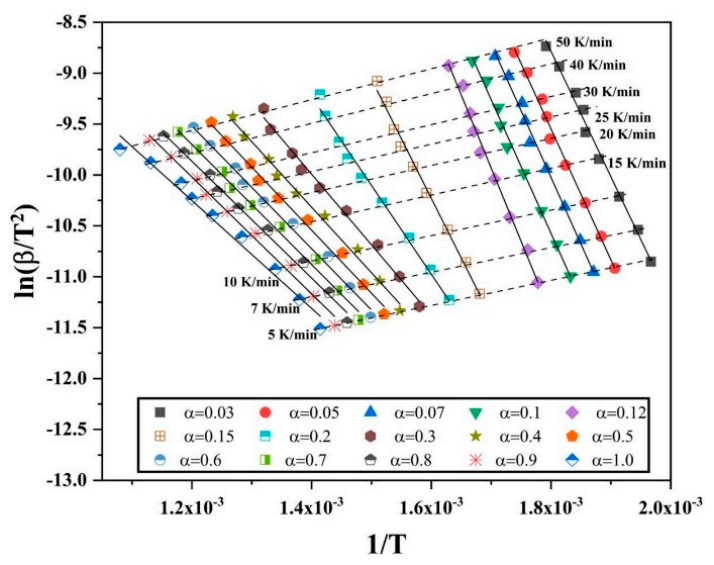

Figure 11. Iscoconversional plots of $\ln \frac{\beta}{T^{2}}$ vs. $\frac{1}{T}$ for different degrees of conversion when reducing $\mathrm{Fe}_{2} \mathrm{O}_{3}$ nanopowder in hydrogen.

Figure 12 shows the variation in activation energy as the degree of conversion changes for $\mathrm{Fe}_{2} \mathrm{O}_{3}$ nanopowder reduced in hydrogen environment. The apparent activation energy for the reduction of $\mathrm{Fe}_{2} \mathrm{O}_{3}$ nanopowder in hydrogen environment varied from 45 to $120 \mathrm{~kJ} / \mathrm{mol}$. This variation in activation energy can be viewed as three distinct ranges according to the slope change. The initial range is $0.03<$ $\alpha<0.15$, for which there is an increase in the apparent activation energy value from 105 to $120 \mathrm{~kJ} / \mathrm{mol}$. The second range, $0.15<\alpha<0.4$, is characterized by a drastic decrease in the value of apparent activation energy from 120 to $55 \mathrm{~kJ} / \mathrm{mol}$. For the third and final range, $0.4<\alpha<1.0$, the activation energy decreases steadily from 55 to $45 \mathrm{~kJ} / \mathrm{mol}$. It is known that the $\alpha<0.15$ corresponds to the reduction of $\mathrm{Fe}_{2} \mathrm{O}_{3}$ to $\mathrm{Fe}_{3} \mathrm{O}_{4}$. The later part of the conversion corresponds to the reduction reaction of $\mathrm{Fe}_{3} \mathrm{O}_{4}$ to $\mathrm{Fe}$. The highest activation energy value in the initial range falls well within the broad range literature values of $75-245 \mathrm{~kJ} / \mathrm{mol}$ for the reduction of $\mathrm{Fe}_{2} \mathrm{O}_{3}$ to $\mathrm{Fe}_{3} \mathrm{O}_{4}$. This reduction demands a higher activation energy in comparison to the second step of reduction which is the reduction of $\mathrm{Fe}_{3} \mathrm{O}_{4}$ to metallic Fe, for which values are between $15-172 \mathrm{~kJ} / \mathrm{mol}$ have been quoted [19,21-23]. Though the value of activation energy is well within the reported range, the trend along the degree of reduction is different in the present case when compared to the reported data [23]. The iron oxide nanopowder used in the present study was crystalline in nature as determined from XRD (Figure 13). Furthermore, Scherrer analysis was performed and the crystallite size was calculated to be $25 \mathrm{~nm}$. Table 1 lists activation energy values for the reduction of iron oxide.

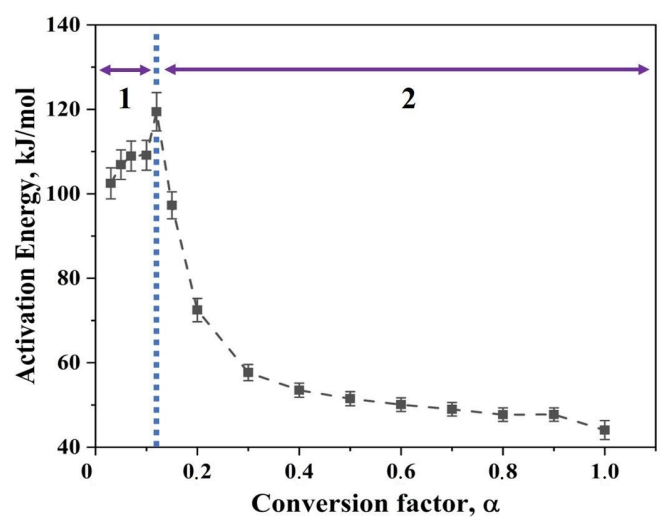

Figure 12. Plot depicting the variation in apparent activation energy as a function of conversion factor, $\alpha$, for $\mathrm{Fe}_{2} \mathrm{O}_{3}$ nanopowder reduced in hydrogen where region 1 is the prereduction step whereas region 2 is the main reduction step. 


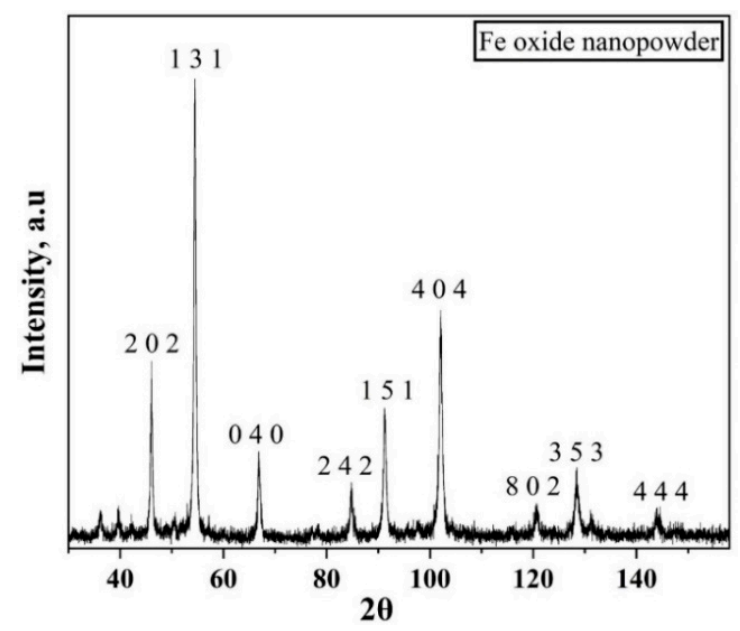

Figure 13. XRD pattern of iron oxide nanopowder showing the crystalline nature of the oxide used in the present study.

Table 1. Apparent activation energy of iron oxide reduction $(\mathrm{kJ} / \mathrm{mol})$.

\begin{tabular}{|c|c|c|c|}
\hline Iron Oxide & $\begin{array}{c}\text { Activation Energy, } \\
\mathrm{kJ} / \mathrm{mol}\end{array}$ & Reduction & Temperature Range, ${ }^{\circ} \mathrm{C}$ \\
\hline $\begin{array}{c}\text { Granulated } \mathrm{Fe}_{2} \mathrm{O}_{3} \\
\text { nanopowder [23] } \\
\alpha-\mathrm{Fe}_{2} \mathrm{O}_{3} \rightarrow \mathrm{Fe}_{2} \mathrm{O}_{3} \rightarrow \mathrm{Fe}\end{array}$ & 75-125 & $\begin{array}{l}\text { Hydrogen reduction, } \\
\text { Isoconversional } \\
\text { approach }\end{array}$ & $320-500$ \\
\hline $\begin{array}{c}\text { Ball milled } \mathrm{Fe}_{2} \mathrm{O}_{3} \\
\text { nanopowder } \\
\text { agglomerates [21] } \\
\alpha-\mathrm{Fe}_{2} \mathrm{O}_{3} \rightarrow \mathrm{Fe}_{2} \mathrm{O}_{3} \rightarrow \mathrm{Fe}\end{array}$ & $20-46$ & $\begin{array}{l}\text { Hygrometry method, } \\
\text { Hydrogen reduction } \\
\text { Isoconversional } \\
\text { approach }\end{array}$ & $270-580$ \\
\hline $\begin{array}{c}\text { Both natural and } \\
\text { laboratory iron oxide } \\
\alpha-\mathrm{Fe}_{2} \mathrm{O}_{3} \rightarrow \mathrm{Fe}_{3} \mathrm{O}_{4}\end{array}$ & 108 & Hydrogen reduction & $250-400$ \\
\hline $\begin{array}{l}99.8 \% \text { pure iron oxide } \\
\alpha-\mathrm{Fe}_{2} \mathrm{O}_{3} \rightarrow \mathrm{Fe}_{3} \mathrm{O}_{4},[19]\end{array}$ & 76 & Hydrogen reduction & $220-683$ \\
\hline$\alpha-\mathrm{Fe}_{2} \mathrm{O}_{3} \rightarrow \mathrm{Fe}_{3} \mathrm{O}_{4},[19]$ & 95 & $\mathrm{H}_{2}-\mathrm{N}_{2}$ & $337-604$ \\
\hline$\alpha-\mathrm{Fe}_{2} \mathrm{O}_{3} \rightarrow \mathrm{Fe}_{3} \mathrm{O}_{4},[19]$ & 114 & $\mathrm{CO}$ & $265-482$ \\
\hline $\mathrm{Fe}_{3} \mathrm{O}_{4} \rightarrow \mathrm{Fe},[19]$ & $39-88$ & Hydrogen reduction & $220-683$ \\
\hline $\mathrm{Fe}_{3} \mathrm{O}_{4} \rightarrow \mathrm{Fe},[19]$ & $36-103$ & $\mathrm{H}_{2}-\mathrm{N}_{2}$ & $337-604$ \\
\hline $\mathrm{Fe}_{3} \mathrm{O}_{4} \rightarrow \mathrm{Fe},[19]$ & $40-114$ & $\mathrm{CO}$ & $265-482$ \\
\hline$\alpha-\mathrm{Fe}_{2} \mathrm{O}_{3} \rightarrow \mathrm{Fe}_{3} \mathrm{O}_{4},[22]$ & 90 & $\begin{array}{c}\text { Temperature } \\
\text { programmed reduction }\end{array}$ & $230-380$ \\
\hline $\mathrm{Fe}_{3} \mathrm{O}_{4} \rightarrow \mathrm{Fe},[22]$ & 70 & $\begin{array}{c}\text { Temperature } \\
\text { programmed reduction }\end{array}$ & $330-730$ \\
\hline $\begin{array}{c}\text { Iron oxide nanopowder } \\
\alpha-\mathrm{Fe}_{2} \mathrm{O}_{3} \rightarrow \mathrm{Fe}_{3} \mathrm{O}_{4} \\
\text { this work }\end{array}$ & $105-120$ & $\begin{array}{l}\text { Hydrogen reduction } \\
\text { Isoconversional } \\
\text { approach }\end{array}$ & $230-430$ \\
\hline $\mathrm{Fe}_{3} \mathrm{O}_{4} \rightarrow \mathrm{Fe}$, this work & $45-55$ & $\begin{array}{l}\text { Hydrogen reduction } \\
\text { Isoconversional } \\
\text { approach }\end{array}$ & $430-680$ \\
\hline
\end{tabular}




\subsection{Kissinger Approach for Iron and Iron Oxide Reduction Kinetics}

Figure 14 shows the Kissinger plots $\left(\ln \left(\frac{\beta}{T_{m}^{2}}\right)\right.$ versus $\left.\frac{1}{T_{m}}\right)$ for reduction of the oxide film on Fe nanopowder of the two different size fractions 40-60 and 60-80 nm, respectively. The slope of the curve was multiplied with $-\mathrm{R}$ and the activation energy values were caculated to be $67.5 \pm 5.0$ and $81.3 \pm 3.4 \mathrm{~kJ} / \mathrm{mol}$ for the $40-60$ and $60-80 \mathrm{~nm}$ particles, respectively. These values lie close to the activation energy values obtained from the isoconversional method for $\alpha=1.0$.

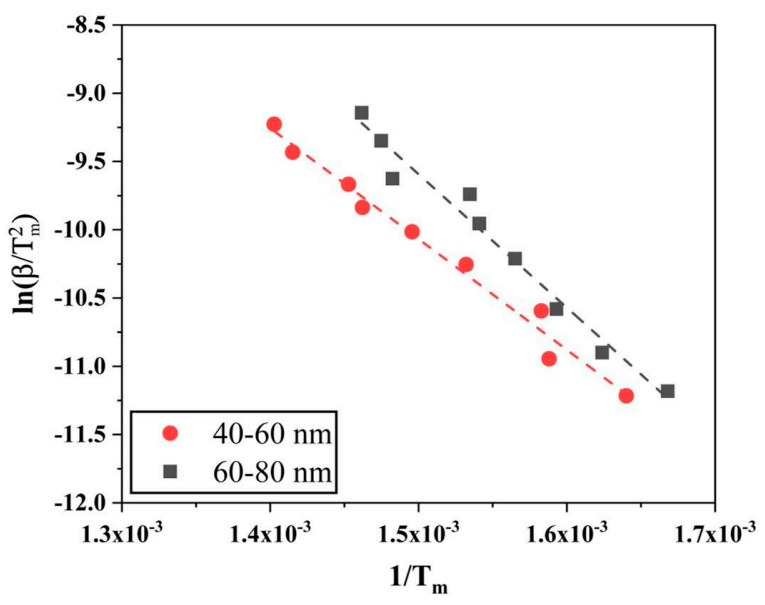

Figure 14. Kissinger plots to evaluate the activation energy for the reduction of surface oxide of Fe nanopowder of sizes (red) 40-60 and (black) 60-80 nm, respectively.

Similar calculations using Kissinger method were done for reduction of $\mathrm{Fe}_{2} \mathrm{O}_{3}$ in hydrogen as well. As the reduction of $\mathrm{Fe}_{2} \mathrm{O}_{3}$ to $\mathrm{Fe}$ is a two-stage process, two different peaks from the DTG graphs (Figure 8) were used and processed for the activation energy values. Figure 15 shows the Kissinger plots for both the first and second peaks of reduction of $\mathrm{Fe}_{2} \mathrm{O}_{3}$. The activation energy for the first reduction step, $\mathrm{Fe}_{2} \mathrm{O}_{3}$ to $\mathrm{Fe}_{3} \mathrm{O}_{4}$, was calculated to be $113.7 \pm 4.9 \mathrm{~kJ} / \mathrm{mol}$, whereas for the second step, $\mathrm{Fe}_{3} \mathrm{O}_{4}$ to $\mathrm{Fe}$, was calculated to be $47.2 \pm 2.5 \mathrm{~kJ} / \mathrm{mol}$.

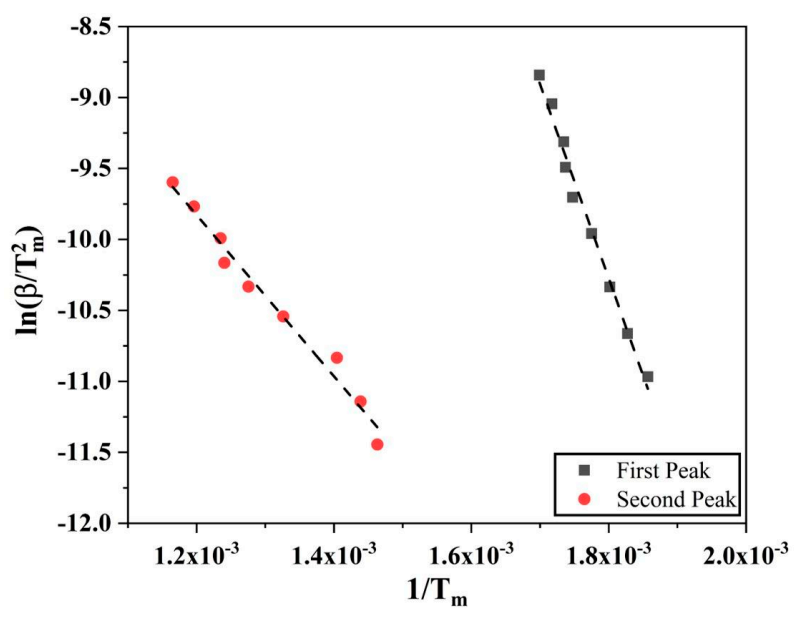

Figure 15. Kissinger plots for the $\mathrm{Fe}_{2} \mathrm{O}_{3}$ to $\mathrm{Fe}_{3} \mathrm{O}_{4}$ and $\mathrm{Fe}_{3} \mathrm{O}_{4}$ to $\mathrm{Fe}$ reduction reactions.

The obtained values from Kissinger method for activation energy were in the range of values calculated using isoconversional approach. A comparison is shown in Table 2. 
Table 2. Activation energy values for different reduction reactions using two different approaches.

\begin{tabular}{ccc}
\hline Reaction & $\begin{array}{c}\text { Activation Energy, } \\
\text { Isoconversional Approach, } \\
\mathbf{k J} / \mathbf{m o l}\end{array}$ & $\begin{array}{c}\text { Activation Energy, } \\
\text { Kissinger Approach, kJ/mol }\end{array}$ \\
\hline $\begin{array}{c}\mathrm{Fe} \text { nanopowder surface oxide } \\
\text { reduction }(40-60 \mathrm{~nm})\end{array}$ & $118-65$ & $62-70$ \\
$\begin{array}{c}\mathrm{Fe} \text { nanopowder surface oxide } \\
\text { reduction }(60-80 \mathrm{~nm})\end{array}$ & $115-71$ & $78-84$ \\
$\mathrm{Fe}_{2} \mathrm{O}_{3}$ nanopowder, $\mathrm{Fe}_{2} \mathrm{O}_{3} \rightarrow \mathrm{Fe}_{3} \mathrm{O}_{4}$ & $105-120$ & $109-117$ \\
$\mathrm{Fe}_{2} \mathrm{O}_{3}$ nanopowder, $\mathrm{Fe}_{3} \mathrm{O}_{4} \rightarrow \mathrm{Fe}$ & $55-45$ & $45-55$ \\
\hline
\end{tabular}

Figure 16 shows a plot comparing the activation energy values using two different approaches. For the isoconversional approach, the values of apparent activation energy were taken when the reduction reaction was complete. The values obtained using two different approaches overlap and are in the range of values from other studies. Although the values obtained using Kissinger method correspond well with the values obtained from isoconversional method for complete reduction, Kissinger method takes absolute temperature values into account. Therefore, it provides a single value for the reduction process. This does not account for the varying activation values as the reaction proceeds and it is the isoconversional approach which offers this in detail.

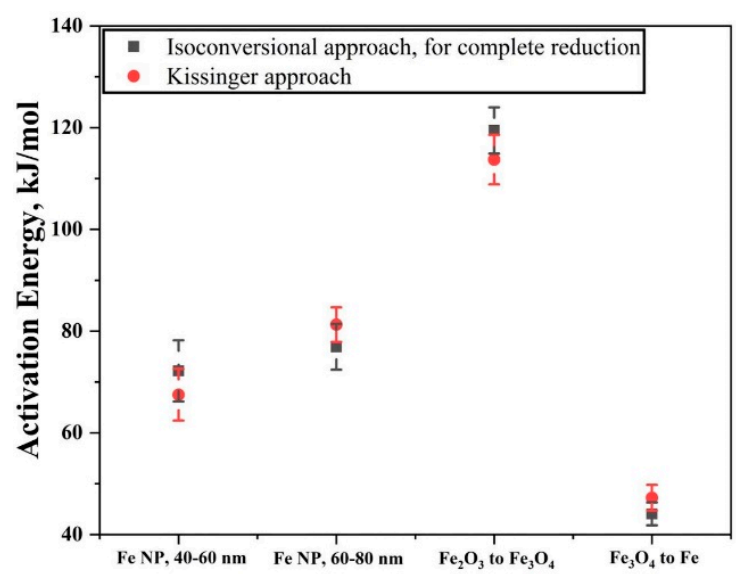

Figure 16. Plot showing the activation energy obtained using isoconversional approach, for full reduction reaction and values obtained using Kissinger approach.

\subsection{Proposed Model}

It is generally accepted that the reduction of iron oxide $\left(\mathrm{Fe}_{2} \mathrm{O}_{3}\right)$, in its bulk form, proceeds via a two-step process to convert to metallic Fe. The same was observed even for the powder and particulate forms. For the reaction where iron oxide is reduced to metallic iron, the mechanism followed depends on the conditions chosen for the analysis [25]. For particulate materials, in the case of coarse particles (millimeter size range), reduction reportedly proceeds via a phase boundary mechanism or topochemical mode of reaction. For finer particles/powder, however, a different reaction mechanism is seen to be operative, particularly at lower temperatures, which is nucleation and growth [26].

In the current study it has been corroborated that even in the nanometer regime, a two-step process is involved in the reduction of iron oxide for the case of nanopowder. For the case of iron nanopowder, a single step reaction is however shown to occur for the reduction of surface iron oxide to metallic Fe.

In this regard, a qualitative model is proposed to further explain the reduction of the surface oxide of iron nanopowder based on the knowledge developed from the reaction kinetics of iron oxide nanopowder (Figure 17) where the oxide layer is assumed to consist of $\mathrm{Fe}_{2} \mathrm{O}_{3}$ (Figure 3). The densities 
of the oxide layers being 5.2 and $5.7 \mathrm{~g} / \mathrm{cm}^{3}$ for $\mathrm{Fe}_{2} \mathrm{O}_{3}$ and $\mathrm{Fe}_{3} \mathrm{O}_{4}$ respectively. The model is based on following assumed conditions:

a. During the prereduction step, $\mathrm{Fe}_{2} \mathrm{O}_{3}$ is reduced to $\mathrm{Fe}_{3} \mathrm{O}_{4}$ completely. As the density of $\mathrm{Fe}_{3} \mathrm{O}_{4}$ is higher than that of $\mathrm{Fe}_{2} \mathrm{O}_{3}$, a porous $\mathrm{Fe}_{3} \mathrm{O}_{4}$ structure is expected upon transformation.

b. The porous $\mathrm{Fe}_{3} \mathrm{O}_{4}$ is reduced to metallic Fe during the main reduction step, resulting in islands of metallic Fe.

c. Catalytic reaction: The freshly formed metallic iron surfaces exhibit an auto-catalytic nature, supporting the chemisorption and disassociation of hydrogen molecules to yield active hydrogen atoms which are transferred or transported from metal surface to the metal/oxide interfaces through 'portholes' of water vapour $[25,27]$.

Through the above conditions a to c, the metal surface is created early on and reactions can proceed in parallel when having oxide film on Fe nanopowder, whereby there will be no clear differentiation of the two reduction stages as observed for the $\mathrm{Fe}_{2} \mathrm{O}_{3}$ reference nanopowder.

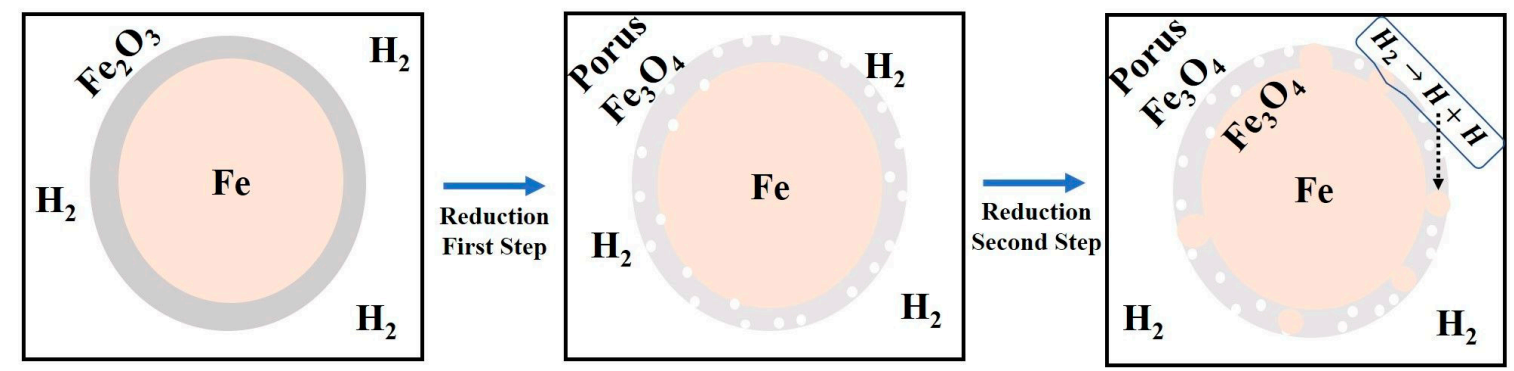

Figure 17. Proposed model for the reduction of surface oxide on iron nanopowder.

\section{Conclusions}

The present study addressed the reaction kinetics for the reduction of oxide film on iron nanopowder in hydrogen, including the comparison with the reduction of $\mathrm{Fe}_{2} \mathrm{O}_{3}$ nanopowder as reference under same conditions. The experiments were done using high sensitivity thermogravimetric analysis and two size ranges of $40-60 \mathrm{~nm}$ and $60-80 \mathrm{~nm}$ of the iron nanopowder were used. The mass loss of about $5 \%$ was recorded for both size fractions of iron nanopowder for all the heating rates up to $50 \mathrm{~K} / \mathrm{min}$. This mass loss corresponds to the complete reduction of the surface oxide, supposed to be mainly $\mathrm{Fe}_{2} \mathrm{O}_{3}$. The mass loss curve showed a single maximum peak, hence indicating that the surface oxide is reduced to metallic Fe in a single stage process. The calculated activation energy from the TG measurements using both isoconversional and Kissinger approach was in the range of the reported data for the reduction of the iron oxide in hydrogen. The TG and DTG analysis of $\mathrm{Fe}_{2} \mathrm{O}_{3}$ revealed instead that the reduction of $\mathrm{Fe}_{2} \mathrm{O}_{3}$ to metallic Fe followed a two-stage process involving first the decomposition $\mathrm{Fe}_{2} \mathrm{O}_{3} \rightarrow \mathrm{Fe}_{3} \mathrm{O}_{4}$ and then the final reduction $\mathrm{Fe}_{3} \mathrm{O}_{4} \rightarrow \mathrm{Fe}$. For the initial range of $\alpha, 0.03<\alpha<0.15$, the activation energy was in the range of 105 to $120 \mathrm{~kJ} / \mathrm{mol}$. This corresponds to the reduction of $\mathrm{Fe}_{2} \mathrm{O}_{3} \rightarrow \mathrm{Fe}_{3} \mathrm{O}_{4}$ in hydrogen. A drastic reduction in the value of activation energy ranging from 120 to $45 \mathrm{~kJ} / \mathrm{mol}$, was observed for $\alpha>0.15$ which corresponded the reduction stage $\mathrm{Fe}_{3} \mathrm{O}_{4} \rightarrow \mathrm{Fe}$. The decreasing trend could be explained using the nucleation and growth model where the activation energy needed for nucleation is higher than needed for growth. The activation energy values fall in the range of reported data for the reduction of iron oxide in hydrogen. The reduced activation energy can be attributed to the catalytic activity of reduced Fe particles which facilitate the reduction of adjacent oxide particles. In conclusion, it can be said that the surface iron oxide is reduced to metallic Fe particles and the newly formed metallic Fe surface accelerates the reduction process by serving as an autocatalytic surface. 
Author Contributions: Conceptualization, methodology, investigation, data curation, formal analysis, writing-original draft and visualization, S.K.M.; conceptualization, investigation, and visualization, J.W.; writing-review, editing, and supervision, E.H.; writing-review, editing, supervision, project administration, and funding acquisition, L.N. All authors have read and agreed to the published version of the manuscript.

Funding: This work has been carried out within the project 'Nanotechnology enhanced sintered steel processing' through support from Swedish Foundation for Strategic Research, SSF within the program 'Generic Methods and Tools for Furture Production'.

Acknowledgments: The authors would like to acknowledge the support from 'Area of Advance, Production', Chalmers University of Technology.

Conflicts of Interest: The authors declare no conflict of interest. The funders had no role in the design of the study; in the collection, analyses, or interpretation of data; in the writing of the manuscript, or in the decision to publish the results.

Data Statement: The raw/processed data required to reproduce these findings cannot be shared at this time as the data also forms part of an ongoing study.

\section{References}

1. Song, J.; Lee, G.-Y.; Hong, E.-J.; Lee, C.S.; Lee, J.-S. Sintering behavior of bimodal iron nanopowder agglomerates. J. Am. Ceram. Soc. 2019, 102, 3791-3801. [CrossRef]

2. Choi, J.-P.; Lyu, H.-G.; Lee, W.-S.; Lee, J.-S. Densification and microstructural development during sintering of powder injection molded Fe micro-nanopowder. Powder Technol. 2014, 253, 596-601. [CrossRef]

3. Dominguez, O.; Champion, Y.; Bigot, J. Liquidlike Sintering Behavior of Nanometric Fe and Cu Powders: Experimental Approach. Metall. Mater. Trans. A Phys. Metall. Mater. Sci. 1998, 29, 2941-2949. [CrossRef]

4. Puri, P.; Yang, V.J. Effect of Particle Size on Melting of Aluminum at Nano Scales. Phys. Chem. C 2007, 111, 11776-11783. [CrossRef]

5. Sun, J.; Simon, S.L. The melting behavior of aluminum nanoparticles. Mater. Acta 2007, 463, 32-40. [CrossRef]

6. Alavi, S.; Thompson, D.L. Molecular Dynamics Simulations of the Melting of Aluminum Nanoparticles. J. Phys. Chem. A 2006, 110, 1518-1523. [CrossRef]

7. Manchili, S.K.; Shvab, R.; Zehri, A.; Ye, L.; Hryha, E.; Liu, J.; Nyborg, L. Surface analysis of iron and steel nanopowder. Surf. Interface Anal. 2018, 50, 1083-1088. [CrossRef]

8. Wendel, J.; Manchili, S.K.; Hryha, E.; Nyborg, L.J. Oxide reduction and oxygen removal in water-atomized iron powder: A kinetic study. Therm. Anal. Calorim. 2020. [CrossRef]

9. Pourghahramani, P.; Forssberg, E. Reduction kinetics of mechanically activated hematite concentrate with hydrogen gas using nonisothermal methods. Thermochim. Acta 2007, 454, 69-77. [CrossRef]

10. Khawam, A.; Flanagan, D.R. Role of isoconversional methods in varying activation energies of solid-state kinetics: II. Nonisothermal kinetic studies. Thermochim. Acta 2005, 436, 101-112. [CrossRef]

11. Vyazovkin, S.J. Advanced isoconversional method. Therm. Anal. 1997, 49, 1493-1499. [CrossRef]

12. Vyazovkin, S.; Wight, C.A. Isothermal and non-isothermal kinetics of thermally stimulated reactions of solids. Int. Rev. Phys. Chem. 1998, 17, 407-433. [CrossRef]

13. Opfermann, J.; Kaisersberger, E. An advantageous variant of the Ozawa-Flynn-Wall analysis. Thermochim. Acta 1992, 203, 167-175. [CrossRef]

14. Friedman, H.L. Kinetics of thermal degradation of char-forming plastics from thermogravimetry. Application to a phenolic plastic. J. Polym. Sci. Part C Polym. Symp. 1964, 6, 183-195. [CrossRef]

15. Vyazovkin, S.J. Modification of the integral isoconversional method to account for variation in the activation energy. Comput. Chem. 2001, 22, 178-183. [CrossRef]

16. Blaine, R.L.; Kissinger, H.E. Homer Kissinger and the Kissinger equation. Thermochim. Acta 2012, 540, 1-6. [CrossRef]

17. Wendel, J.; Shvab, R.; Cao, Y.; Hryha, E.; Nyborg, L. Surface analysis of fine water-atomized iron powder and sintered material. Surf. Interface Anal. 2018, 50, 1065-1071. [CrossRef]

18. Yamashita, T.; Hayes, P. Analysis of XPS spectra of Fe 2+ and Fe 3+ ions in oxide materials. Appl. Surf. Sci. 2008, 254, 2441-2449. [CrossRef]

19. Pineau, A.; Kanari, N.; Gaballah, I. Kinetics of reduction of iron oxides by H2: Part I: Low temperature reduction of hematite. Thermochim. Acta 2006, 447, 89-100. [CrossRef] 
20. Sastri, M.V.C.; Viswanath, R.P.; Viswanathan, B. Studies on the reduction of iron oxide with hydrogen. Int. J. Hydrogen Energy 1982, 7, 951-955. [CrossRef]

21. Jung, S.S.; Lee, J.S. In-situ kinetic study of hydrogen reduction of $\mathrm{Fe}_{2} \mathrm{O}_{3}$ for the production of Fe nanopowder. Mater. Trans. 2009, 50, 2270-2276. [CrossRef]

22. Lin, H.-Y.; Chen, Y.-W.; Li, C. The mechanism of reduction of iron oxide by hydrogen. Thermochim. Acta 2003, $400,61-67$.

23. Lee, G.Y.; Song, J.1.; Lee, J.S. Reaction kinetics and phase transformation during hydrogen reduction of spherical $\mathrm{Fe}_{2} \mathrm{O}_{3}$ nanopowder agglomerates. Powder Technol. 2016, 302, 215-221. [CrossRef]

24. Colombo, U.; Gazzarrini, F.; Lanzavecchia, G. Mechanisms of Iron Oxides Reduction at Temperatures below $400{ }^{\circ}$ C. Mater. Sci. Eng. 1967, 2, 125. [CrossRef]

25. Viswanathan, R.P.; Viswanathan, B.; Sastri, M.V.C. Kinetics of reduction of $\mathrm{Fe}_{2} \mathrm{O}_{3}$ to $\mathrm{Fe}_{3} \mathrm{O}_{4}$ by the constant temperature differential thermal anaiysis method. Thermochim. A 1976, 16, 240-244. [CrossRef]

26. Wimmers, O.J.; Arnoldy, P.; Moulijn, J.A. Determination of the Reduction Mechanism by TemperatureProgrammed Reduction: Application to Small $\mathrm{Fe}_{2} \mathrm{O}_{3}$ Particles. J. Phys. Chem. 1986, 632, 1331-1337.

27. Tiernan, M.J.; Barnes, P.A.; Parkes, G.M.B. Reduction of Iron Oxide Catalysts: The Investigation of Kinetic Parameters Using Rate Perturbation and Linear Heating Thermoanalytical Techniques. J. Phys. Chem. B 2001, 105, 220-228. [CrossRef]

(C) 2020 by the authors. Licensee MDPI, Basel, Switzerland. This article is an open access article distributed under the terms and conditions of the Creative Commons Attribution (CC BY) license (http://creativecommons.org/licenses/by/4.0/). 